\title{
Bone marrow necrosis in antiphospholipid syndrome
}

\author{
S Paydas, R Koçak, S Zorludemir, F Baslamisli
}

\begin{abstract}
Bone marrow necrosis (BMN) is a relatively rare entity and has been associated with a poor prognosis. It is most commonly found in patients with neoplastic disorders, severe infections and sickle cell anemia. An unusual case of antiphospholipid syndrome (APS) with extensive bone marrow necrosis is described in a 27 year old woman. The patient presented with severe pancytopenia, some cognitive impairment resulting from a previous cerebrovascular accident, fever, hypertension, dyspnoea, tachycardia, hepatosplenomegaly, and vaginal bleeding. Her laboratory findings included a strongly positive Coombs' test (anti-IgG and antiC3d), a prothrombin time of 23 seconds and an activated partial thromboplastin time of 45 seconds. Anticardiolipin antibody tests were positive. Antinuclear and anti-DNA antibodies were negative but the anti-SM test was positive. A bone marrow biopsy specimen was reported as showing extensive necrosis. The patient was treated with steroids, transfusion, and plasma exchange with some clinical improvement but her pancytopenia did not respond and necessiated frequent transfusions. This case lends further support to the association between APS and BMN. (F Clin Pathol 1997;50:261-262)
\end{abstract}

Keywords: anticardiolipin antibody; antiphospholipid syndrome; bone marrow necrosis.

\section{Case report}

Çukurova University Faculty of Medicine Balcali, Adana, Turkey:

Department of

Oncology

S Paydas

\section{Department of}

Haematology

R Koçak

F Baslamisli

Department of

Pathology

S Zorludemir

Correspondance to: Professor S Paydas,

C.ukurova University Faculty of Medicine, Department of Oncology, 01330 Balcali,

Adana, Turkey.

Accepted for publication 5 November 1996
A 27 year old woman was admitted to hospital with severe pancytopenia (haemoblobin concentration $62 \mathrm{~g} / \mathrm{l}$, white blood cell count $3.2 \times 10^{9} / 1$ and platelet count $\left.13 \times 10^{9} / 1\right)$. She had a medical story of nine miscarriages or still births in the previous five years. Three years ago she had also had a cerebrovascular accident which resulted in some intellectual impairment. The patient was not taking any medication

Her clinical findings consisted of some cognitive impairment, fever, hypertension, dyspnoea, tachycardia, hepatosplenomegaly, and vaginal bleeding. Her laboratory findings included, apart from pancytopenia, a strongly positive Coombs' test (anti-IgG and anti-C3d), a prothrombin time of 23 seconds and an activated partial thromboplastin time of $45 \mathrm{sec}-$ onds. Anticardiolipin antibody tests, using an ELISA (Immunowell), were positive: IgG phospholipid $215 \mathrm{U} / \mathrm{l}$, and IgM phospholipid $48 \mathrm{U} / 1$ (normal range $0-11 \mathrm{U} / \mathrm{l}$ ). One week later, IgG phospholipid was $205 \mathrm{U} / 1$ and $\operatorname{IgM}$ phospholipid was $59 \mathrm{U} / 1$. The antinuclear and anti-DNA antibodies were negative but the anti-SM test was positive. Several attempts at aspirating bone marrow failed (dry tap), and a bone marrow biopsy specimen was reported as showing extensive necrosis (fig 1 ).

The patient was treated with steroids $(2 \mathrm{mg} /$ $\mathrm{kg} /$ day), transfusion (five units), and plasma exchange (five times with $8920 \mathrm{ml}$ plasma) with some clinical improvement but her pancytopenia did not respond and necessiated frequent transfusions. Thirty two days after being admitted to hospital, the patient discharged herself.

\section{Discussion}

Bone marrow necrosis (BMN) is a rare pathological entity that is usually associated with malignant neoplasm when diagnosed in living patients. Leukaemia, lymphoma, metastatic carcinoma, and sarcoma have all been associated with BMN. ${ }^{1}$ BMN has also been observed in non-infectious and non-neoplastic conditions such as the sickle cell diseases (haemoglobin SS, haemoglobin SC, sickle $\beta$ thalassaemia). ${ }^{2}$

Antiphospholipid syndrome (APS) is a relatively new entity and is associated with a diverse set of clinical manifestations including venous and arterial thrombosis, recurrent fetal loss, thrombocytopenia, and neurological disorders. ${ }^{3}$ The patients may or may not have systemic lupus erythematosus. We recently encountered a patient with APS and BMN. The association of these two conditions has been reported recently by Bulvik et al. ${ }^{4}$ In fact, similar morphological features have previously been reported in relation to DIC induced by toxaemia and in a patient with a history of recurrent abortion and thromboembolic episodes. ${ }^{56}$ However, no information about antiphospholipids was given in these reports. The case reported here lends further support to the association between APS and BMN.

The pathogenesis of BMN is poorly understood. The best accepted mechanism is vascular obstruction in the bone marrow. In neoplastic disorders, widespread microvascular obstruction may result from compression by rapidly proliferating cells or from intrinsic vascular obstruction by tumoral microthrombi. Possible contributory factors include therapeutic irradiation, chemotherapy, and the higher oxygen requirement of neoplastically transformed bone marrow. ${ }^{7} \mathrm{BMN}$ may be caused by the toxic effects of chemotherapy or indirectly by the release of toxins, cytokines or vasoactive 


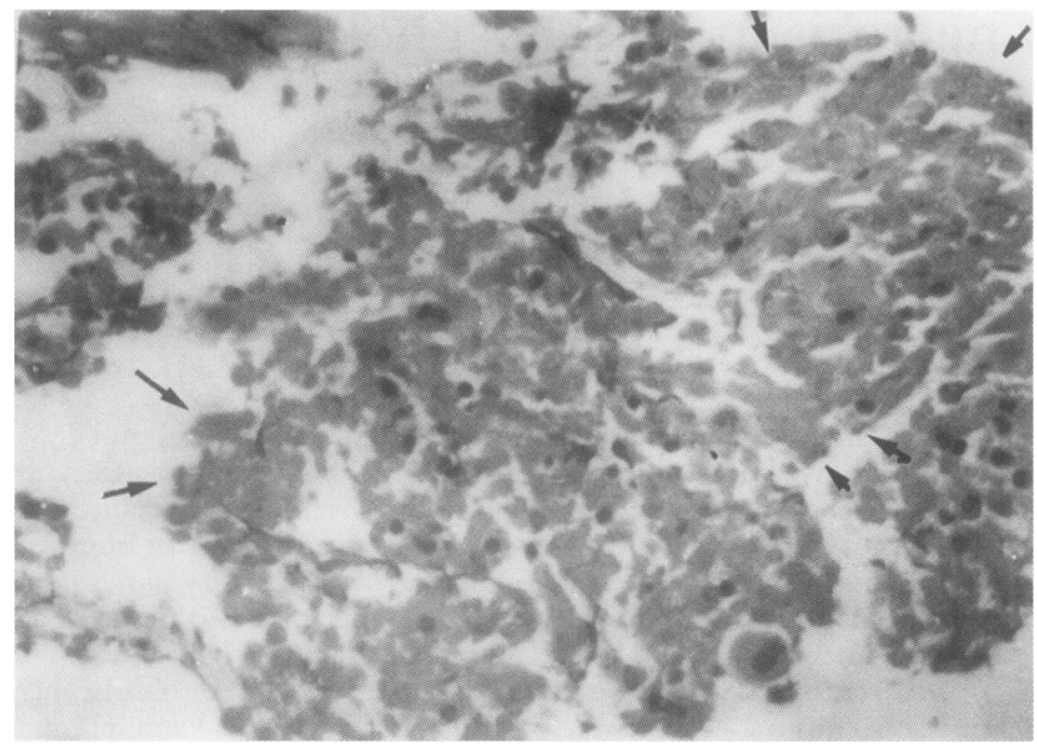

Figure 1 Bone marrow biopsy specimen showing areas of widespread necrosis (arrows).

substances from damaged tumour cells following the administration of drugs. ${ }^{8}$ For example, tumour necrosis factor is implicated in mediating BMN in some patients with cancer. ${ }^{9}$ Alterations in bone marrow microcirculation can lead to ischaemia and subsequent necrosis. ${ }^{8}$ The pathogenesis of BMN associated with APS is also unclear. As suggested by Bulvik et al, vascular thrombosis may follow damage to endothelial cells by the antiphospholipid antibodies. Abnormal fibrinolysis, platelet activation, and abnormal antithrombin III activity are other possibilities. ${ }^{4}$ These mechanisms need to be defined further.
It is possible that raised anticardiolipin antibody titre are reponsible for bone marrow necrosis. However, there is no clear association between phospholipid titre and disease severity. ${ }^{10}$ The phospholipid antibody titre in our patient was very high. The predominant anticardiolipin antibody in our patient was IgG type, as was the case reported by Bulvik et al (70 and $12 \mathrm{U} / 1$ for IgG and IgM, respectively). ${ }^{4}$ In another of our patients with APS, but without $\mathrm{BMN}$, IgM predominated (35 and $170 \mathrm{U} / 1$ for IgG and IgM, respectively). This finding suggests that there may be an association between chronic APS and the development of BMN.

1 Crown JD, Rubin RN, Kies MS, Cerezo P. Bone marrow necrosis. Cancer 1980;46:2168-71.

2 Kiraly JF, Wheby MS. Bone marrow necrosis. Am f Med 1976;60:361-8.

3 Sammaritano LR, Gharavi AE, Lockshin MD. Antiphospholipid syndrome: immunologic and clinical aspects. Semin Arthritis Rheum 1990;20:81-96.

4 Bulvik S, Aronson I, Ress S, Jacobs P. Extensive bone marrow necrosis associated with antiphospholipid antibodies. Am f Med 1995;98:572-4.

5 Rose MS. Apparent necrosis of bone marrow in a patient with disseminated intravascular coagulation, post partum. Lancet 1973;ii:730-1.

6 Koickerbocker WJ, Quenville NF. Widespread marrow necrosis during pregnancy. Skeletal Radiol 1982;9:37-40.

7 Mehta K, Pawel BR, Gadol C. Bone marrow necrosis in leukemic phase follicular lymphoma. Arch Pathol Lab Med 1991;115:89-92.

8 Aboulafia DM, Demirer T. Fatal bone marrow necrosis following fludarabine administration in a patient with indolent lymphoma. Leuk Lymphoma 1995;19:1951-3.

9 Knupp C, Pekala PH, Cornelius P. Extensive bone marrow necrosis in patients with cancer and tumor necrosis activity in plasma. Am f Hematol 1988;29:215-9.

10 Lockshin MD. Antiphospholipid antibody syndrome. FAMA 1992;268:1451-3. 